\title{
Option selection in whole-body rotation movements in gymnastics
}

CDD. 20.ed. 796.41

Thomas HEINEN*

http://dx.doi.org/10.1590/1807-55092016000100029

Marc NICOLAUS"

\begin{abstract}
When a gymnast performs a somersault, the linear and angular momentum along with a particular control of inertia during the flight phase constrain the possibilities for action. Given the complexity and dynamic nature of the human moving system, one could argue that there exist a particular amount of stable coordination states when performing somersaults. The goal of this study was to explore the manifold of movement options and coordination states along with their differentiating parameters for a single somersault in gymnastics based on a simple mathematical model reflecting gymnast's rotation behavior during the flight phase. Biomechanical parameters determining rotation behavior during a somersault were systematically varied with regard to a particular set of biomechanical constraints defining a successful somersault performance. Batch simulations revealed that from 10229760 simulation cycles only 655346 (approximately $6.41 \%$ ) led to successful somersault performance. A subsequent analysis of the movement option landscape for the optimum angular momentum revealed ten coordination states for a single somersault that could be clearly distinguished based on the simulation parameters. Taken the results together, it becomes apparent that it may be most advisable to perform a single somersault with a larger moment of inertia when achieving the tucked position, a longer duration to achieve the tucked position, a longer duration of staying tucked, and an intermediate moment of inertia during landing. This strategy comprises the largest amount of movement options associated with an upright landing and thus the highest probability of success when performing a single somersault.
\end{abstract}

KEY WoRDs: Linear momentum; Angular momentum; Moment of inertia; Somersault; Coordination states; Prospective control strategy.

\section{Introduction}

Imagine a gymnast taking off the floor for performing a single tucked somersault: linear momentum and angular momentum along with a particular control of inertia during the flight phase constrain the gymnast's possibilities for action during the somersault ${ }^{1-2}$. However, there is still a manifold of action possibilities that would result in an upright landing at the end of the somersault ${ }^{3}$. Notwithstanding the manifold of action possibilities as well as the complexity and dynamic nature of the human moving system, performing somersaults is not an indiscriminate task. One could rather argue that first, there exist a particular amount of stable coordination states, with each state comprising a particular amount of movement options for a single somersault, and second, that the inherent dynamics of the gymnast's moving system constrain the possibilities for action, and therefore the amount of coordination states when performing somersaults ${ }^{4-5}$. The questions would be, first, which are the principal coordination states when performing a single somersault, and second, which parameters differentiate between these coordination states? - Therefore the goal of this study was to explore the manifold of movement options and coordination states along with their differentiating parameters for a single somersault in gymnastics based on a simple mathematical model reflecting gymnast's rotation behavior during the flight phase.

Performers possess a repertoire of stable coordination states when enganged in goal-directed activity (metaphorically called the 'perceptualmotor landscape') that developed as a result of learning and practice ${ }^{4}$. One coordination state comprises a particular amount of variability, and 
thus a particular set of movement options that could be described by a specific configuration of biomechanical parameters ${ }^{6}$. A particular movement option is defined as a distinct and measurable behavioral trajectory the gymnast can adopt in a given situation ${ }^{3}$. Dynamical systems tend to inhabit only a particular amount of all (hypothetically) possible coordination states, depending on existing conditions and constraints ${ }^{7}$. Since the pioneering works of Kelso ${ }^{8-9}$ this has not only been explicitly shown for fine motor skills, such as finger or hand movements ${ }^{10}$, but also for gross motor skills, such as walking or running ${ }^{11}$. More recent research showed that this seems to be also true for more complex skills such as rotations with and without flight phases in gymnastics ${ }^{12-13}$. Seen in the long term, the aforementioned repertoire of coordination states is (continually) influenced and shaped by several factors such as genes, perceptions, or cognitions ${ }^{14-16}$. Seen in the short term, the layout of the perceptualmotor landscape comprises the coordination states satisfying the current configuration of constraints when performing (complex) skills? .

Constraints can in principle be classified as either informational or physical ${ }^{4,17}$. While informational constraints are the various energy sources and flows in a (moving) system, physical constraints are the numerous variables that define the variety of movement options a human being is technically able to realize ${ }^{18}$. For example, the distribution of moment of inertia when being in a tucked body posture is a physical constraint that directly influences the angular velocity a gymnast is able to generate at a given angular momentum during the flight phase of a somersault ${ }^{19-20}$. When gymnasts perform a somersault there is of course a significant degree of flexibility in the control of moment of inertia. Gymnasts could theoretically adopt any time-course of the moment of inertia about the somersault axis that comprises inertia values between a most extended body posture and a most tucked body posture. However, in order to perform a successful somersault, gymnasts' must control their moment of inertia in a way that landing in an upright position is possible ${ }^{21}$.

Experts seem to adapt their behavior to the operating constraints. In this context, a prospective control strategy has been postulated to operate when performing somersaults. In one study, different control strategies in the performance of backward somersaults were evaluated ${ }^{22}$. Therefore the authors analyzed motor behavior of backward somersaults in gymnasts (Experiment 1), as well as between experts and novices in vision and novision conditions (Experiment 2). Results of both experiments revealed that expert gymnasts regulated their body orientation during the flight phase relative to the ground. This pattern of results was not found when visual information was suppressed, arguing in favor of a prospective control strategy [see also LeE et al. ${ }^{23}$ ]. Somersaults are thus guided on the basis of information about whether or not an upright landing will occur if current conditions persist. More generally speaking, expert gymnasts are thought to adapt their (rotational) behavior to the environmental constraints ${ }^{18}$.

Given that physical constraints are thought to directly influence the number of available movement options and thus are likely to influence the movement option selected in a particular situation, it is postulated that the inherent dynamics of the gymnast's moving system constrain the possibilities for action when performing somersaults ${ }^{4-5}$. This postulation would at least have four implications: First, the manifold of movement options when performing a somersault should comprise a particular amount of stable coordination states reflecting a successful performance of a somersault ${ }^{9}$. Second, these individual states differ in regard to the likelihood of success when performing a somersault ${ }^{18}$. Third, these states comprise a particular amount of functional variability and they are likely to differ in regard to a particular configuration of biomechanical parameters ${ }^{6}$. Fourth, among all individual states there should at least exist one optimum for a given set of constraints ${ }^{24}$.

The goal of this study was therefore to explore the manifold of movement options for a single somersault in gymnastics. To approach this goal, a simple simulation model for single somersaults in gymnastics was developed. This model comprised a defined configuration of constraints mimicking gymnast's rotation behavior when performing single forward somersaults. It was hypothesized that there exists a defined amount of stable states reflecting the successful performance of a somersault, and that these states are likely to differ in regard to a particular configuration of biomechanical parameters. However, there was neither a specific prediction on the definite amount of stable states, nor on the configuration of biomechanical parameters differentiating between the different states, but it was sought to explore these aspects based on the results of the simulation model. 


\section{Method}

\section{Task description}

The modeled motor task was a tucked forward somersault, performed with the help of a miniature trampoline as a takeoff surface ${ }^{25}$. FIGURE 1 presents a stick-figure sequence of the experimental task. After a short run-up, the gymnast places his/her feet on the trampoline bed to prepare the subsequent somersault. The somersault can be described by three movement phases: 1) takeoff phase; 2) flight phase; and 3) landing phase ${ }^{3,19}$. During the takeoff phase, the gymnast has to generate sufficient linear and angular momentum, which allows him/her to have enough time in the air in order to perform a full body rotation about the somersault axis during flight ${ }^{24}$.

When performing a tucked or a piked somersault, the flight phase is usually characterized by a particular coordination of the gymnast's moment of inertia, in order increase or decrease angular velocity, and thus to achieve a particular amount of rotation about the somersault axis ${ }^{24}$. The gymnast usually takes off from the trampoline bed with an upright body posture (and thus a rather larger moment of inertia). During the first part of the flight phase he/ she tucks or pikes the body. After remaining tucked or piked for a short duration, the gymnast extends his/her body towards landing ${ }^{26}$. Therefore, the flight phase can further be subdivided in three parts (see FIGURE 1): 2a) a part during which the gymnasts achieves the tucked/piked position, 2b) a part during which he/she remains tucked/piked, and 2c) a part in which he/she extends her body towards the landing. Finally, the somersault should be landed in an upright position on both feet with no additional steps. During landing, the gymnast reduces his/her angular momentum to zero ${ }^{19,26}$.

Moments of inertia have been estimated using different methods for various body segments and different body axes ${ }^{19,27-28}$. FIGURE 2 presents the calculated moments of inertia about the somersault axis for different body postures of a female gymnast. Gymnasts' moments of inertia were calculated following the mathematical approach for a segmental analysis presented in ENOKA ${ }^{19}$ (p.6674). Anthropometric measurements were derived from high-resolution photographs (cf., FIGURE 2).

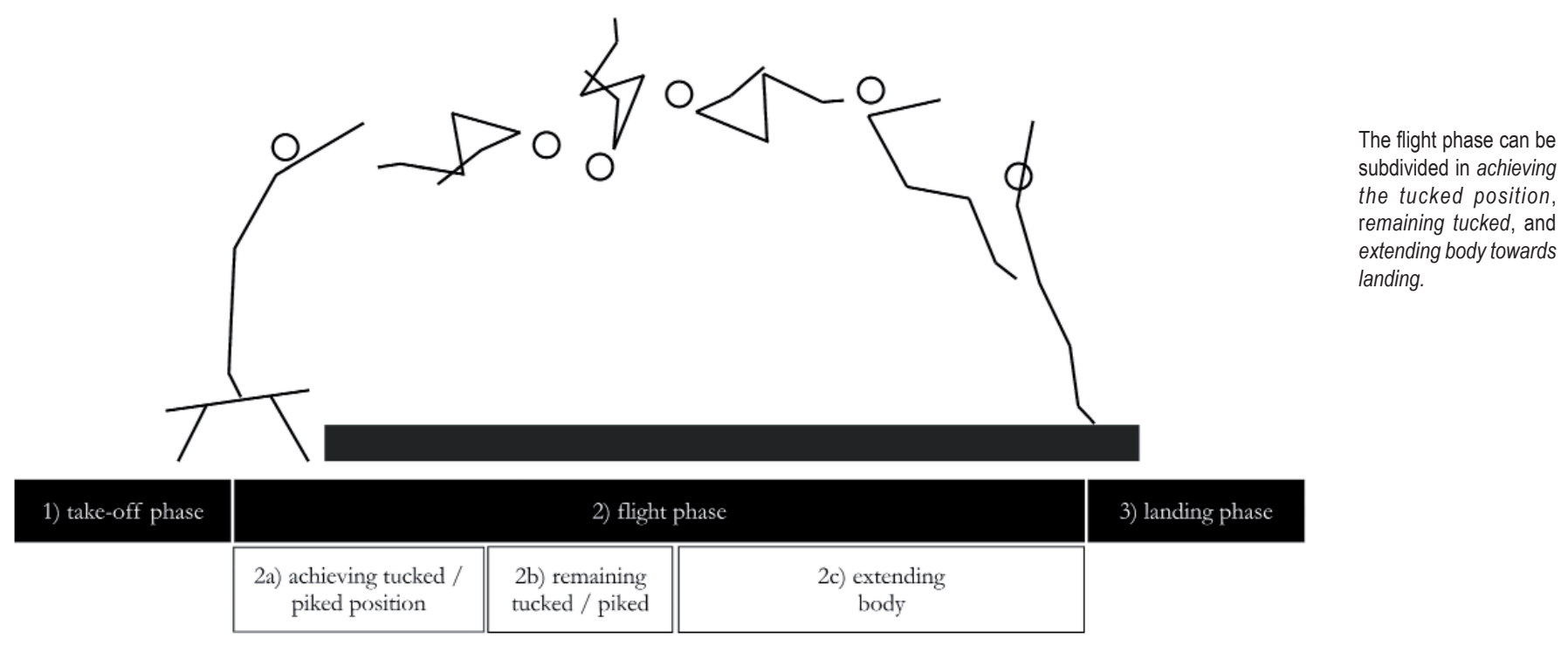

FIGURE 1 - Schematic stick-figure sequence and corresponding movement phases of the motor task. 
A piked body position corresponded to a value of $4.6 \mathrm{~kg} \mathrm{~m}^{2}$ whereas a tucked body position corresponded to a value of $2.4 \mathrm{~kg} \mathrm{~m}^{2}$ to $3.7 \mathrm{~kg}$ $\mathrm{m}^{2}$, depending on how close the gymnast put her body segments to the center of mass.
In this example the gymnast reduces his/her moment of inertia from $12.4 \mathrm{~kg} \mathrm{~m}^{2}\left(I_{\text {TO }}\right)$ to about $3.5 \mathrm{~kg} \mathrm{~m}^{2}\left(I_{\text {MIN }}\right)$ during the first $200 \mathrm{msec}$ of the flight phase $\left(\Delta t_{\text {group }}\right)$. The gymnast remains tucked for about $170 \mathrm{msec}$ $\left(\Delta t_{\text {tucked }}\right)$ and increases his/her moment of inertia to about $11.4 \mathrm{~kg}$ $m^{2}\left(I_{\text {LAND }}\right)$ towards the landing $\left(\Delta t_{\text {extend }}\right)$.
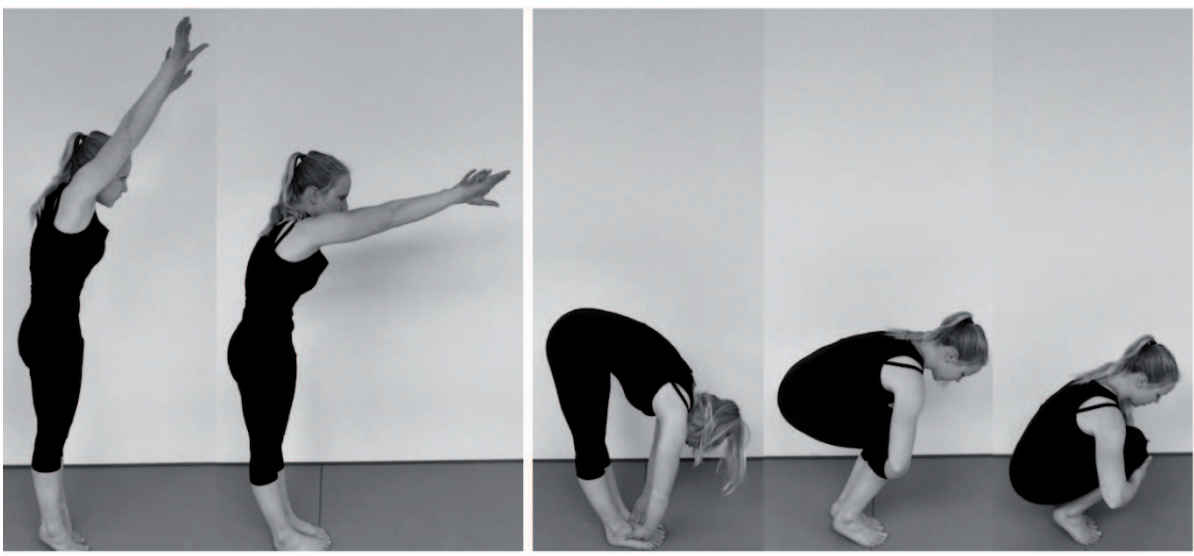

\section{4}

11.4
3.7

\section{$2.4 \mathrm{~kg} \cdot \mathrm{m}^{2}$}

FIGURE 2 -Exemplary values of the moment of inertia $\left[\mathrm{kg} \mathrm{m}^{2}\right]$ about the somersault axis for different body postures of a female gymnast ${ }^{19}$.

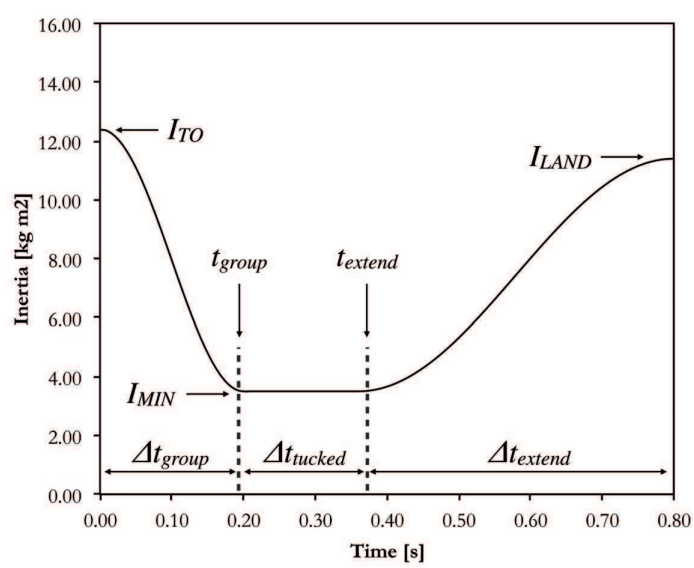

a)

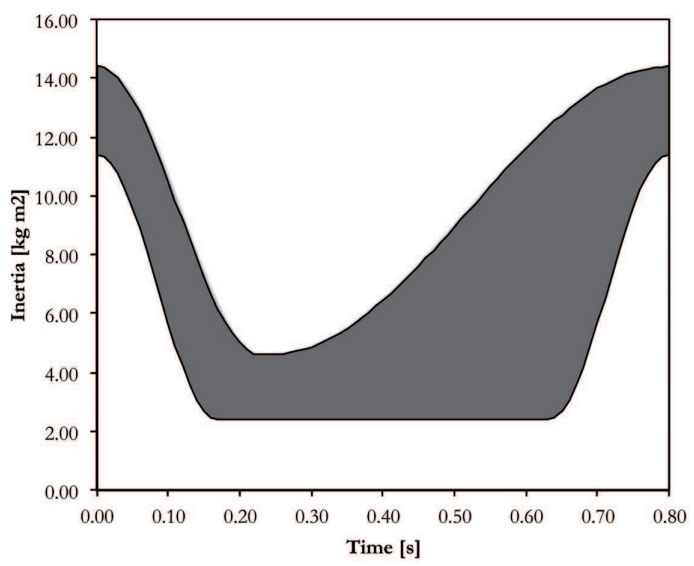

b)

FIGURE 3 - a) Prototypical time course of the gymnast's moment of inertia about the somersault axis during the flight phase of a tucked forward somersault; b) Parameter space (grey area) of all time courses of gymnast's moment of inertia about the somersault axis during a flight phase of a tucked forward somersault, given the biomechanical constraints of the somersault.

\section{Biomechanical constraints}

There are several biomechanical constraints that determine a full whole-body rotation in a somersault. First, the amount of gymnast's linear and angular momentum determine the flight phase of the somersault. In any object with a fixed mass that rotates about a particular symmetry axis, the angular momentum can be expressed as a product of the objects' moment of inertia and its angular velocity $^{20}$ (see Equation 1):

$$
H=I \omega \Rightarrow \omega(t)=\frac{H}{I(t)}
$$

$I$ represents the moment of inertia of the object, $\omega$ is the angular velocity, and $H$ is the angular momentum. Given that the angular momentum can be assumed to remain constant during the flight phase, due to the physical relation between impulse and momentum ${ }^{19}$, the angular velocity of a gymnast when somersaulting is directly determined by the moment of inertia (Equation 1).

Second, and as mentioned above, the flight phase of the somersault can be subdivided in three parts that directly correspond to the time-course of the moment of inertia (FIGURE 3a). During the first part, the gymnast achieves a tucked/piked position and thus reduces his/her initial moment of inertia $\left(I_{T O}\right)$ to a particular value $\left(I_{M I N}\right)$ in a particular time duration $\left(\Delta t_{\text {group }}\right)$. During the second part, the gymnast remains in a particular tucked/piked 
position and thus the moment of inertia remains constant during a particular time duration $\left(\Delta t_{\text {tucked }}\right.$ $\left.=\Delta t_{\text {extend }}-\Delta t_{\text {group }}\right)$ During the third part, the gymnast extends his/her body towards the landing position and thus increases his/her moment of inertia towards a particular value $\left(I_{L A N D}\right)$ in a particular time duration $\left(\Delta t_{\text {extend }}\right)$. The time course of the moment of inertia of the part during which the gymnast remains tucked/piked can be best described by a constant value. The time course of the moment of inertia during the parts where the gymnast achieves the tucked/piked position and where the gymnast extends his/her body can be best described by means of partial cosine functions. Combining these assumptions with Equation 1 gives the following system of equations (Equation 2):

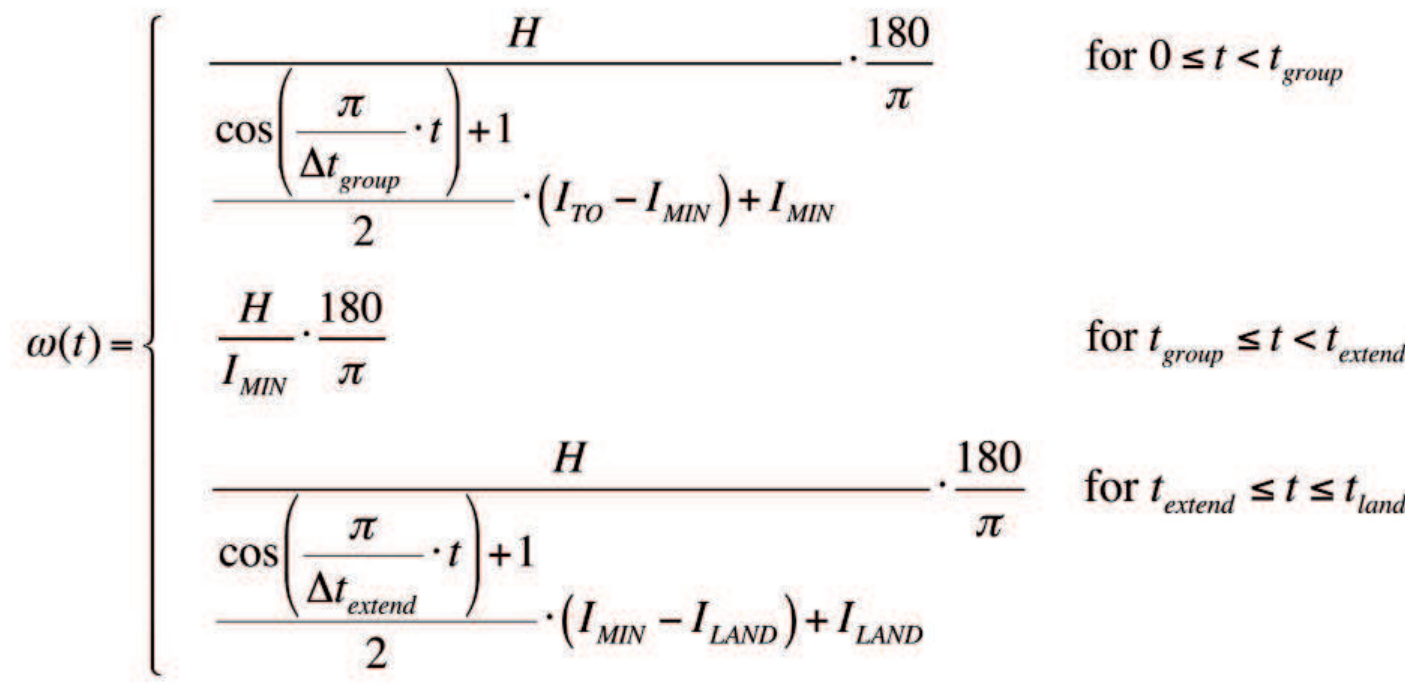

$O$ denotes the takeoff from the trampoline bed and $t_{\text {land }}$ represents the duration of the flight phase. $I_{T O}, I_{M I N}$ and $I_{L A N D}$ represent values of the moment of inertia (during takeoff, when being tucked/piked, and during landing), and tgroup as well as textend indicate discrete time values of the time course of the moment of inertia (when achieving the tucked/ piked position and when starting to extend the body towards the landing; see FIGURE 3a). $\Delta t$ denotes the duration of achieving the tucked/ piked position and $\Delta t_{\text {extend }}$ represents the duration of extending the body towards landing.

Third, the angle that a gymnast rotates during a particular flight phase is determined by the angular velocity due to the physical relation between rotated angle and angular velocity ${ }^{29}$. Given that the angular velocity changes during the flight phase of a somersault, the accumulated rotated angle changes as a function of the time-course of the angular velocity. Thus the antiderivatives of the equations in (Equation 2) give an estimation of the rotated angle in the three parts of the flight phase of the somersault (Equation 3): $\alpha=\omega t$

(Eq. 3)

$\alpha$ represents the rotated angle and $t$ represents the duration of the flight phase. As indicated by Equation 2 and Equation 3, the rotated angle during the flight phase of a somersault is in principle be determined by the time-course of the moment of inertia with a given angular momentum.

Fourth, gymnasts usually exhibit a slight forward inclination of the trunk during takeoff and a slight backward inclination during landing ${ }^{30}$. The inclination during takeoff is mainly a result of the linear and angular impulse during the takeoff phase given a particular body posture and velocity when hitting the trampoline bed. The backward inclination during landing supports the absorption of gymnast's rotation to zero, enabling the gymnast to land with an upright posture ${ }^{26}$. Given the inclination during takeoff and the inclination during landing, the overall angle of rotation can be estimated to about $305^{\circ}$ to $325^{\circ}$ for a single somersault ${ }^{29,31}$. 


\section{Simulation procedure}

Modeling of movement options during somersaulting was realized in a two-step approach. First, the parameter space of the simulation was defined (see FIGURE 3b). The definition of the parameter space comprised the definition of functional ranges of the following values: 1 ) values for moment of inertia during takeoff and during landing ranged from 11.4 to $14.4 \mathrm{~kg} \mathrm{~m}$; 2) moment of inertia when being tucked ranged from 2.4 to $4.6 \mathrm{~kg} \mathrm{~m}$ m $^{2}$ (see FIGURE $2)$; 3) flight duration was set to the constant value of $800 \mathrm{msec}$; 4) time duration to achieve the tucked position ranged from 170 to $230 \mathrm{msec}$, equaling 21.25 to $28.75 \%$ of the flight duration; 5) time duration to remain in the tucked position ranged from 0 to 460 msec, equaling 21.25 to $78.75 \%$ of the flight duration; and 6) angular momentum ranged from 20 to $60 \mathrm{Nm}$ s. An illustrated overview of the parameter space can be found in FIGURE 3b (grey area).

Second, the simulation step size for varying the values of moment of inertia, time duration, and angular momentum were defined and batch simulations were conducted. Moment of inertia values were varied in steps of $0.2 \mathrm{~kg} \mathrm{~m}^{2} 32-33$. Time durations were varied in steps of $20 \mathrm{msec}^{34}$, and angular momentum was

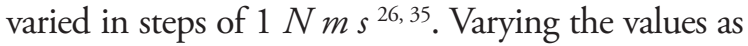
written above comprised simulation cycles representing all (theoretically) conceivable movement options for a single forward somersault under the defined constraints. One simulation cycle was marked as successful if the model produced a somersault rotation angle between $305^{\circ}$ and $325^{\circ}$.

\section{Data analysis}

In a first step, the total amount of successful movement options was summed up for each angular momentum value. A potential value was calculated, first by dividing the amount of successful movement options for one value of angular momentum by the total amount of successful movement options, and

\section{Results}

It was hypothesized that there exists a defined amount of stable coordination states reflecting the successful performance of a somersault, and that these states are likely to differ in regard to a particular configuration of biomechanical parameters. However, second by inverting and rescaling the resulting values between 0.00 and $1.00^{36}$. The lower the calculated potential value was, the more probable was a successful performance of the forward somersault. A potential value of 1.00 indicated that there was no movement option that resulted in a somersault rotation between $305^{\circ}$ and $325^{\circ}$. A potential value of 0.00 indicated that the corresponding value of angular momentum comprised the movement option that most likely would result in an upright landing. The analysis resulted in a V-shaped relationship between movement options in a forward somersault and angular momentum during the flight phase (see Results section). The distribution comprised a global minimum at an angular momentum value of $39 \mathrm{Nm} \mathrm{s}$.

In a second step, the distribution of successful movement options was explored for an angular momentum value of $39 \mathrm{~N} \mathrm{~m} \mathrm{~s}$. A median split procedure was utilized for the following five variables: 1) moment of inertia during takeoff; 2) moment of inertia when achieving the tucked position; 3) moment of inertia during landing; 4) time duration to achieve the tucked position, and 5) time duration to remain in the tucked position. This resulted in a total of 32 categories of parameter combinations. For each parameter combination the amount of successful movement options was summed up, and a potential value was calculated. Therefore the amount of successful movement options for a particular category was divided by the overall amount of movement options. In an additional step, the calculated values were inverted and rescaled to range between 0.00 and 1.00. Again, the lower the calculated potential value was, the more probable was a successful performance of the forward somersault, while a value of 1.00 indicated that there was no movement option that resulted in a somersault rotation between $305^{\circ}$ and $325^{\circ}$, and a potential value of 0.00 indicated that the corresponding value of angular momentum comprised the movement option that most likely would result in an upright landing.

there was neither a specific prediction on the definite amount of stable states, nor on the configuration of biomechanical parameters differentiating between the different states, but it was sought to explore these aspects based on the results of the simulation model. 
In a first step, the total amount of successful movement options was summed up for each angular momentum value, and a potential value ranging from 0.00 to 1.00 was calculated. The movement options were successful for angular momentum values between $22 \mathrm{Nms}(n=279)$ and $57 \mathrm{Nms}$ $(n=4)$, showing a $\mathrm{V}$-shaped potential distribution (see FIGURE 4). An angular momentum of less than $21 \mathrm{Nm} s$ always resulted in under-rotating the somersault, and a value of more than $57 \mathrm{Nm}$ $s$ resulted always in over-rotating the somersault in the used model. In total, there were 10229760 simulation cycles in the range between $21 \mathrm{Nm}$ $s$ and $57 N m$ s. From the 10229760 simulation cycles, 655346 (approximately 6.41\%) were found to result in a somersault rotation between $305^{\circ}$ and $325^{\circ}$, thereby comprising valid and successful movement options in the performance of a single forward somersault. FIGURE 4 illustrates the relationship between movement options in a tucked forward somersault and angular momentum during the flight phase. An angular momentum of $39 \mathrm{Nm}$ $s$ resulted in a maximum value of 38119 possible movement options for a single forward somersault under the given constraints, thereby reflecting a global optimum for the single somersault in the mathematical model used in this study.

In a second step, the distribution of successful movement options was explored for an angular momentum value of $39 \mathrm{Nm} \mathrm{s}$. In total there were 276480 simulation cycles from which 38119 (approximately 13.79\%) were successful, thereby resulting in a somersault rotation between $305^{\circ}$ and $325^{\circ}$. FIGURE 5 illustrates a one-dimensional projection of the corresponding movement option landscape when performing a tucked somersault with an angular momentum of $39 \mathrm{Nm}$. Visual inspection revealed that there exist ten valleys in the movement option landscape that are clearly distinguishable from each other, representing different (stable) coordination states of the somersault. While the valleys \#1 and \#6 represent the most stable states, the valleys \#2 and \#7 exhibit a slightly less stable state. Valleys \#4, \#5, \#9, and $\# 10$ represent less stable states and valleys \#3 and \#8 represent the least stable states. Each of the ten valleys corresponded to a particular configuration of simulation parameters.

Moment of inertia during takeoff differentiated between states \#1 to \#5, and \#6 to \#10. While a larger moment of inertia during takeoff was associated with states \#1 to \#5, a smaller moment of inertia during takeoff was related to states \#6 to \#10. State \#1 and state \#6 comprised a larger moment of inertia when achieving the tucked position, a longer duration to achieve the tucked position, a longer duration of remaining tucked, and an intermediate moment of inertia during landing. States \#2 and \#7 comprised a shorter duration to achieve the tucked position and a larger moment of inertia during landing. States \#4, \#5, \#9 and \#10 comprised a smaller moment of inertia when achieving the tucked position along with a rather short duration of remaining in the tucked position, and a larger moment of inertia during landing. States \#3 and \#8 comprised a shorter duration when achieving the tucked position, a shorter duration when remaining tucked, and a smaller moment of inertia during landing.

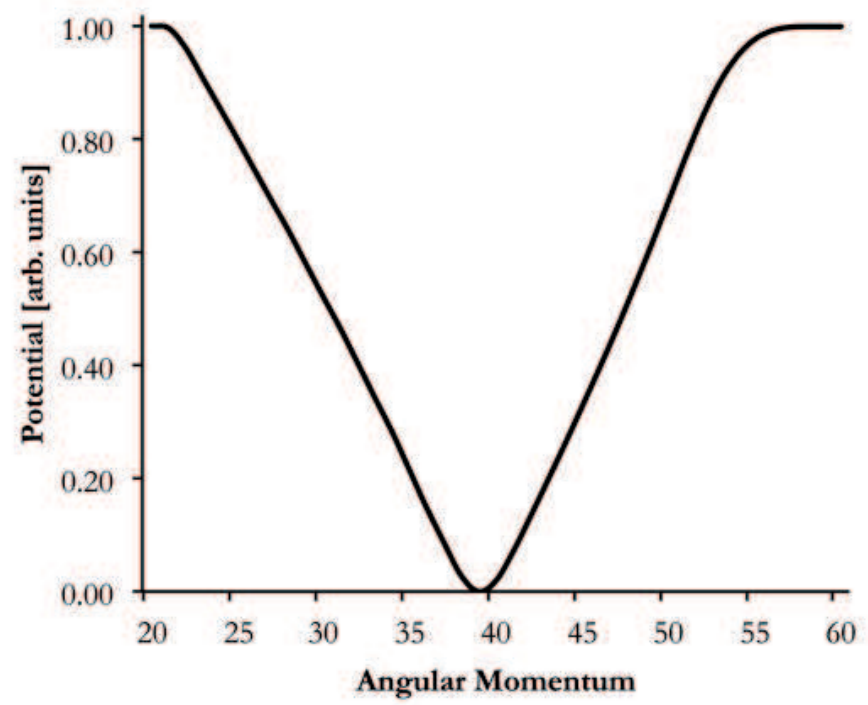

Movement options were transformed to a potential value with arbitrary units, ranging from 0.00 to 1.00 . The lower the value, the more probable a successful performance of the forward somersault was. A potential value of 1.00 indicated that there was no movement option that resulted in a somersault rotation between $305^{\circ}$ and $325^{\circ}$.

FIGURE 4 - Relationship between movement options in a tucked forward somersault and angular momentum during the flight phase. 
Movement options are transformed to a potential value with arbitrary units. The lower the value, the more probable a successful somersault performance was.

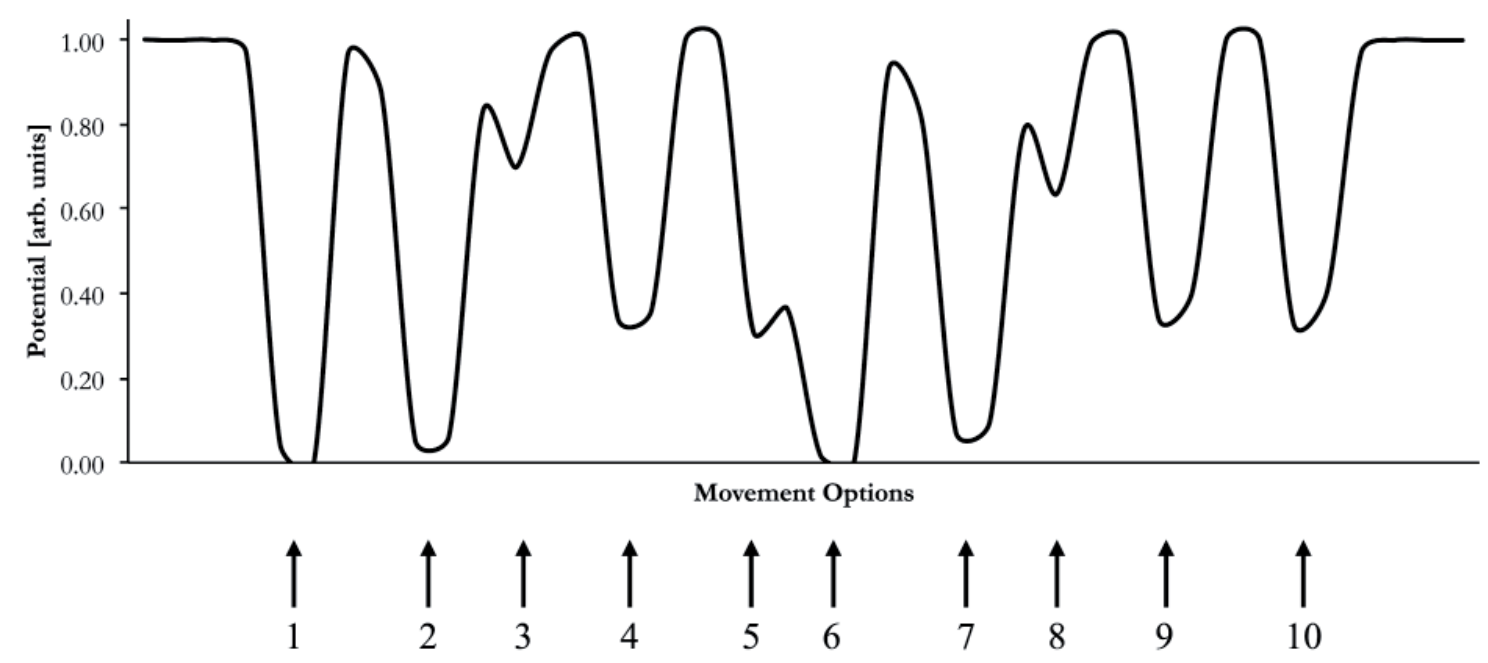

FIGURE 5 - One-dimensional projection of a movement option landscape when performing a tucked forward somersault with an angular momentum of $39 \mathrm{~N} \mathrm{~m}$.

\section{Discussion}

When gymnasts perform a somersault, the linear and angular momentums along with a particular control of inertia during the flight phase constrain the possibilities for action during the somersault ${ }^{2}$. However, there is still a manifold of movement options that would result in an upright landing at the end of the somersault ${ }^{3}$. It was postulated that the inherent dynamics of the gymnast's moving system constrain the possibilities for action when performing somersaults. The main goal of this study was therefore to explore the manifold of movement options by utilizing a simple simulation model for single somersaults in gymnastics. This model comprised a defined configuration of constraints mimicking gymnast's rotation behavior when performing single forward somersaults. It was hypothesized that there exists a defined amount of stable states reflecting the successful performance of a somersault, and that these states are likely to differ in regard to a particular configuration of biomechanical parameters.

Results revealed that the defined parameter space of the simulation model comprised a total amount of 10229760 movement options, from which 655346 (approximately 6.41\%) were found to result in a somersault rotation between $305^{\circ}$ and $325^{\circ}$, thereby reflecting a successful somersault performance. When inspecting the amount of movement options across all simulated values for angular momentum, a global maximum became apparent, thereby indicating that a value of $39 \mathrm{Nm} s$ best satisfied the given physical constraints of the somersaults in the simulation model. Ten coordination states could be distinguished from each other, whereby each state could be characterized by a particular configuration of biomechanical parameters. In addition, each state comprised a different degree of stability and variability. Sport technique in expert performers is usually characterized by a particular optimization tendency ${ }^{37}$. Concerning the results of the simulation model, the probability for performing a successful single somersault is highest at an angular momentum value of $39 \mathrm{Nm}$, and the probability to either under rotate or over rotate the somersault is highest at angular momentum values of less than $21 N m s$ and more than $57 N m s$. Therefore one clear optimization tendency could be to perform the somersault with an angular momentum that comprises the largest amount of movement options associated with an upright landing, and therefore the highest probability of success.

This optimization strategy could be even more important in light of a prospective control strategy. Somersaults are thought to be guided on the basis of information about whether or not an upright landing will occur if current conditions persist ${ }^{22}$. This would also imply that regulative processes could take action in case an upright landing will not occur if current conditions persist. This would automatically imply to change from the currently selected behavioral trajectory to another movement 
option in a given situation that will then result in an upright landing. The more options are available in a given situation the more likely it is that a somersault will result in an upright landing. This may especially be the case where influences such as stress or fatigue are likely to influence performance ${ }^{38}$. Additionally, novices and experts may rely on different informational variables when performing complex skills ${ }^{18}$, and thus exhibit different strategies to perform complex skills ${ }^{23}$.

There are some limitations of this study and two specific aspects should be highlighted. First, it was hypothesized that there exists a particular amount of stable states reflecting successful performance of a somersault. The simulation model in this study should reflect gymnasts' rotation behavior in a single forward somersault performed with a miniature trampoline as a takeoff surface and with a particular set of biomechanical constraints. Thus the question arises if the results of the model are generalizable to multiple forward somersaults performed with a miniature trampoline as takeoff surface, to single forward somersaults performed with another takeoff surface, and/or to backward or sideward somersaults performed either with a trampoline as takeoff surface or not. Given the high complexity of the human moving system it seems likely that different skills comprise different coordination states reflecting successful performance depending on the structural similarity between skills ${ }^{39}$. A subsequent study could therefore be conducted with the aim of exploring the movement option space of gymnastics skills, systematically differing in task demands and/ or structural similarity. Second, the simulation model first and foremost included the time-course of gymnast's moment of inertia in order to model gymnast's behavior during the flight phase of the somersault. Moment of inertia, however, is a result of the spatial configuration of body segments. Thus different configurations of body segments could result in the same moment of inertia, and a subsequent study could target the question if there are particular coordination strategies on the level of body segment configuration that in turn shape the movement option states in a somersault ${ }^{40}$.

There are some practical consequences of this study so far. The results of the simulation model highlight which parameters differ between more and less successful movement option states when performing a forward somersault with a miniature trampoline as a takeoff surface. Given that these differences are grounded in the intrinsic dynamics of the gymnast's moving system a coach could target the particular parameter values during training. On the one hand, and according to the results of this study it may be most advisable trying to perform the somersault with a larger moment of inertia when achieving the tucked position, a longer duration to achieve the tucked position, a longer duration of staying tucked, and an intermediate moment of inertia during landing. On the other hand, performing somersaults with a smaller moment of inertia when achieving the tucked position, a shorter duration of achieving the tucked position, and/or a shorter duration of remaining tucked may be not advisable according to the results of this study.

The selection of an appropriate, yet optimal movement option when performing a single forward somersault with a miniature trampoline should consider the intrinsic dynamics of the moving system and may thus be of high importance in the successful execution of a forward somersault.

\section{Resumo}

Opções de movimentos na rotação da ginástica

Quando um ginasta executa um mortal, o momento linear e angular, juntamente com determinado controle de inércia durante a fase de voo, restringem as possibilidades de ação. Devido à complexidade e à natureza dinâmica do sistema do movimento humano, pode-se argumentar que existe determinada quantidade de estados coordenativos estáveis quando se executa mortais. 0 objetivo deste estudo foi explorar a multiplicidade de opções de movimento e estados coordenativos, juntamente com os seus parâmetros de diferenciação para um único mortal na ginástica, com base em um modelo matemático simples que reflita o comportamento da rotação do ginasta durante a fase de voo. Os parâmetros biomecânicos que determinam o comportamento da rotação durante um mortal variam sistematicamente em relação a determinado conjunto de restrições biomecânicas que definem a execução bem sucedida do mortal. Simulações em 
série revelaram que, a partir de 10229760 ciclos de simulação, somente 655346 (aproximadamente 6,41\%) levaram ao desempenho bem sucedido do mortal. Uma análise subsequente da perspectiva de movimento para o momento angular ótimo revelou 10 estados de coordenação para um único mortal que poderiam ser claramente distinguidos com base nos parâmetros de simulação. Considerados os resultados em conjunto, torna-se evidente que seria mais aconselhável realizar um único mortal com momento de inércia maior quando se atinge a posição grupada, duração mais longa para atingir a posição grupada, duração mais longa da posição grupada, e um momento de inércia intermediário durante a aterrissagem. Essa estratégia compreende a maior quantidade de opções de movimento associados a uma aterrissagem na posição ereta e, assim, a maior probabilidade de sucesso quando se realiza um único mortal.

PalavaAs-Chave: Momento linear; Momento angular; Momento de inércia; Mortal; Estados coordenativos; Estratégia de controle prospectivo.

\section{References}

1. Arkaev LI, Suchilin NG. How to create champions: the theory and methodology of training top-class gymnasts. Oxford: Meyer \& Meyer Sport; 2004.

2. Yeadon MR, Mikulcik EC. Stability and control of aerial movements. In: Nigg BM, MacIntosh BR, Mester J, editors. Biomechanics and biology of movement. Champaign: Human Kinetics; 2000. p.211-21.

3. Raab M, de Oliveira RF, Heinen T. How do people perceive and generate options? In: Raab M, Hekeren H, Johnson JG, editors. Progress in brain research. Amsterdam: Elsevier; 2009. Vol. 174, Mind and motion: the bidirectional link between thought and action. p.49-59.

4. Davids K, Button C, Bennett S. Dynamics of skill acquisition: a constraints-led approach. Champaign: Human Kinetics; 2008.

5. Warren, WH. The dynamics of perception and action. Psych Rev. 2006;113:358-89.

6. Latash ML, Scholz JP, Schöner G. Motor control strategies revealed in the structure of motor variability. Exerc Sport Sci Rev. 2002;30:26-31.

7. Kauffman SA. The origins of order: self-organization and selection in evolution. New York: Oxford University Press; 1993.

8. Haken H, Kelso JAS, Bunz H. A theoretical model of phase transitions in human hand movements. Biol Cybern. 1985;51:347-56.

9. Kelso JAS. Dynamic patterns: the self-organization of brain and behavior. Cambridge: MIT; 1995.

10. Fitzpatrick P, Schmidt RA, Lockman JL. Dynamical patterns in the development of clapping. Child Dev. 1996;67: 2691-708

11. Li L, van den Bogert ECH, Caldwell GE, van Emmerik REA, Hamill J. Coordination patterns of walking and running at similar speed and stride frequency. Hum Mov Sci. 1999;18:67-85.

12. Hiley MJ, Wangler R, Predescu G. Optimization of the felge on parallel bars. Sport Biomech. 2009;8:39-51.

13. Williams GKR, Irwin G, Kerwin DG, Newell KM. Biomechanical energetic analysis of technique during learning the longswing on the high bar. J Sport Sci. 2015;33:1376-87.

14. Newell KM, Liu Y-T, Mayer-Kress G. Learning in the brain-computer interface: insights about degrees of freedom and degeneracy from a landscape model of motor learning. Cogn Process. 2006;6:37-47.

15. Schöllhorn WI, Mayer-Kress G, Newell KM, Michelbrink M. Time scales of adaptive behavior and motor learning in the presence of stochastic perturbations. Hum Mov Sci. 2009;28:319-33.

16. Thelen E, Smith LB. A dynamic systems approach to the development of cognition and action. Cambridge: MIT; 1994.

17. Newell KM. Constraints on the development of coordination. In: Wade MG, Whiting HTA, editors. Motor development in children: aspects of coordination and control. Dordrecht: Martinus Nijhoff; 1986. p.341-60.

18. Fajen BR, Riley MA, Turvey MT. Information, affordances, and the control of action in sport. Int J Sport Psychol. 2008;40:79-107.

19. Enoka RM. Neuromechanics of human movement. 3rd ed. Champaign: Human Kinetics; 2002.

20. Sands WA. Angular kinetics applied to gymnastics. In: Jemni M, editor. The science of gymnastics. New York: Routledge; 2011. p. 94-103.

21. Fajen BR. Affordance-based control of visually guided action. Ecol Psychol. 2007;19:383-410. 
22. Bardy BG, Laurent M. How is body orientation controlled during somersaulting? J Exp Psychol Human. 1998;24: 963-77.

23. Lee DN, Young DS, Rewt D. How do somersaulters land on their feet? J Exp Psychol Human. 1992;18:1195-202.

24. Yeadon MR. Aerial movement. In: Zatsiorsky VM, editor. Biomechanics in sport: performance enhancement and injury prevention. Oxford: Blackwell Science; 2000. p.273-83.

25. Turoff F. Artistic gymnastics: a comprehensive guide to performing and teaching skills for beginners and advanced beginners. Dubuque: Wm C. Brown; 1991.

26. Brüggemann GP. Biomechanics of gymnastic techniques. Sport Sci Rev. 1994;3:79-120.

27. Nigg BM, Herzog W. Biomechanics of the musculo-skeletal system. 2nd ed. New York: John Wiley; 1994.

28. Kwon Y-H. Experimental simulation of an airborne movement: applicability of the body segment parameter estimation methods. J Appl Biomech. 2001;17:232-40.

29. Sands WA, Holvoet P. Angular kinematics applied to gymnastics. In: Jemni M, editor. The science of gymnastics. New York: Routledge; 2011. p.76-84.

30. George GS. Championship gymnastics: biomechanical techniques for shaping winners. Carlsbad: Designs for Wellness; 2010.

31. Heinen T. Evidence for the spotting hypothesis in gymnasts. Motor Control. 2011;15:267-84.

32. Knoll K. Entwicklung von biomechanischen Messplätzen und Optimierung der Sporttechnik im Kunstturnen [Development of biomechanical measuring stations and optimization of movement technique in gymnastics]. Cologne: Sport und Buch Strauss; 1999.

33. Kerwin DG, Yeadon MR, Lee SC. Body configuration in multiple somersault high bar dismounts. Int J Sport Biomech. 1990;6:147-56.

34. Latash ML. Neurophysiological basis of movement. 2nd ed. Champaign: Human Kinetics; 2008.

35. Gervais P, Tally F. The beat swing and mechanical descriptors of three horizontal bar release-regrasp skills. J Appl Biomech. 1993;9:66-83.

36. Stergiou N, Buzzi UH, Kurz MJ, Heidel J. Nonlinear tools in human movement. In: Stergiou N, editor. Innovative analysis of human movement. Champaign: Human Kinetics; 2004. p.63-90.

37. Lees A. Technique analysis in sports: a critical review. J Sport Sci. 2002;20:813-28.

38. Chase MA, Magyar MT, Drake BM. Fear of injury in gymnastics: self-efficacy and psychological strategies to keep on tumbling. J Sport Sci. 2005;23:465-75.

39. Rein R, Button C, Davids D, Summers J. Cluster analysis of movement patterns in multiarticular actions: a tutorial. Motor Control. 2010;14:211-39.

40. Yeadon MR, King MA. Biomechanical simulation models of sports activities. In: Hong Y, Bartlett R, editors. Routledge handbook of biomechanics and human movement science. New York: Routledge; 2008. p.367-79.

\begin{tabular}{r|r} 
ENDEREço & \\
Thomas Heinen & Recebido para publicação: 07/12/2015 \\
Institute of Sport Science & Aceito: 11/01/2016 \\
University of Hildesheim & Universitaetsplatz 1 \\
31141 - Hildesheim - GERMANY & \\
il: thomas.heinen@uni-hilsheim.de &
\end{tabular}

